\title{
La formación digital del estudiante universitario digital: competencias, necesidades y pautas de actuación
}

\section{Digital literacy of university digital students: competences, needs and action guidelines}

\author{
Alba María Hernández-Sánchez ${ }^{1}$ \\ https://orcid.org/0000-0002-3245-6868 \\ Consejería de Educación de la Junta de Andalucía, España \\ Rocío Quijano López ${ }^{2}$ \\ https://orcid.org/0000-0002-6989-3244 \\ Miguel Pérez Ferra ${ }^{3}$ \\ https://orcid.org/0000-0002-3580-6472 \\ Universidad de Jaén, España
}

Recibido: 05-01-2019

Aceptado: 20-03-2019

\section{Cita Recomendada}

Hernández-Sánchez, A., Quijano, R. \& Pérez, M. (2019). La formación digital del estudiante universitario digital: competencias, necesidades y pautas de actuación. Hamut'ay, 6(1), 19-32. http://dx.doi.org/10.21503/hamu.v6i1.1572

\section{RESUMEN}

El presente estudio pretende identificar el nivel de competencia digital del estudiante universitario al inicio de su formación como futuro maestro o maestra, así como comprender las necesidades de formación digital en coherencia con su futuro desempeño profesional. De manera que se contraste que el desempeño de la competencia digital es heterogéneo y carente en función a las habilidades que implican pensamiento de orden superior.

La población de estudio se compone de 559 estudiantes de primer curso de magisterio de las universidades de Granada, Jaén y Oviedo que han cumplimentado un cuestionario "ad hoc" validado por jueces expertos con un alfa de Cronbach de 0.791 de 51 ítems con respuesta graduada tipo Likert sobre la competencia digital.

El estudio descriptivo evidencia la falta de homogeneidad competencial dentro del grupo de nativos y nativas digitales. Observándose un buen desempeño generalizado en torno a actividades como el almacenamiento, la recuperación, la presencia, la participación, el mantenimiento y el potencial creativo. Mientras que, por el contrario, se muestra un desempeño con claras carencias a nivel de evaluación y gestión de la información, filtrado y uso crítico, aplicación de disposiciones legales, creación de materiales y autonomía en la resolución de problemas.

Con todo, el perfil competencial que demuestran los resultados de investigación requiere de una

1 Es maestra funcionaria facilitadora de la inclusión, licenciada en Psicopedagogía y doctora en CC. de la Educación. Líneas de investigación: inclusión educativa, discapacidad y enseñanza a distancia. E-mail: albamaria@ugr.es

2 Es profesora en el Departamento de Didáctica de las Ciencias de la Universidad de Jaén, Catedrática de Escuela Universitaria. Líneas de investigación: formación del profesorado, desarrollo de competencias, enseñanza de las ciencias. E-mail: rquijano@ujaen.es.

3 Es maestro, licenciado en Pedagogía y en Filosofía, doctor en CC.de la Educación, con mención de Premino Extraordinadio, Catedrático de Universidad. Líneas de investigación: Asesoramiento Curricular, formación en competencias e identidad profesional docente. E-mail: mperez@ujaen.es 
necesidad formativa procesual, práctica, transversal, significativa y contextualizada inminente que desarrolle las habilidades de pensamiento de orden superior de los futuros docentes.

Palabras Clave: Educación Superior, nativo digital, competencia digital, tecnologías.

\section{Abstract}

The present study aims to identify the level of digital competence of university students at the beginning of their training as future teachers; as well as to understand the needs of digital training in coherence with their future professional performance. In such a way as to contrast that the performance of digital competence is heterogeneous and devoid in relation to the abilities that involve high order thinking skills.

The study population consists of 559 first-year pedagogy students from the universities of Granada, Jaén and Oviedo who have completed an "ad hoc" questionnaire validated by expert judges with a Cronbach's alpha of 0.791 out of 51 items with a Likert type graded answer about digital competence.

The descriptive study shows the lack of competence homogeneity within the group of digital natives. We observed a good generalized performance regarding activities such as storage, recovery, presence, participation, maintenance and creative potential. While, on the other side, it shows a performance with clear deficiencies at the level of evaluation and information management, filtering and critical use, application of legal provisions, creation of materials and autonomy in problem solving.

Therefore, the competence profile shown by the research results requires a procedural, practical, transversal, significant and contextualized imminent formative training that foster high order thinking skills of future teachers.

Keywords: Higher education, digital native, digital competence, technologies.

\section{INTRODUCCIÓN}

El presente estudio es parte de una investigación de $\mathrm{I}+\mathrm{D}+\mathrm{i}$, denominada: "Evaluación y desarrollo de dos competencias genéricas en estudiantes de primer año del grado de Maestro en Educación Primaria, con referencia: EDU2015-70491-R". El mismo pretende profundizar en la formación actual del estudiante universitario desde una visión de "nativo digital" y cuáles son sus necesidades de formación, con respecto a las TIC, como estudiante del Título de Grado de Magisterio en Educación Primaria. La importancia del presente trabajo surge desde la relevancia que se le confiere a las competencias transversales en la Declaración de Bolonia (1999), redefiniendo los espacios de logro a adquirir por los futuros profesionales.

En el presente siglo la evolución tecnológica ha repercutido de forma significativa en todas las áreas de la sociedad, concretamente en la Educación Superior, tanto a nivel de institución educativa como en las características de los estudiantes (Gisbert \& Esteve, 2011). Bajo este marco se han generado nuevas modalidades de formación que redefinen los fines formativos. Estas circunstancias auspician procedimientos que permiten a los estudiantes generar conocimiento a partir de la información previa. Ello sitúa a la competencia digital más allá de acciones que la reduzcan a la búsqueda y difusión de información. Por el contrario, también aborda el desarrollo de la 
capacidad de seleccionar la información, entenderla, procesarla, organizarla y transformarla en conocimiento, aplicándola a diferentes situaciones y contextos (Gewerc \& Montero-Mesa, 2015; Pérez-Ferra, Quijano-López, \& Ocaña-Moral, 2013). Por lo que la competencia digital constituye un eje transversal necesario en la formación de los universitarios (Gabarda, Rodríguez-Martín \& Moreno-Rodríguez, 2017), razón por la que la situación actual de la formación de los futuros profesionales de la docencia está mediada por el uso de la competencia digital (Sandoval, Rodríguez-Alveal \& Maldonado, (2017), ya que promueve el desarrollo de la empatía, la escucha activa, la asertividad o la capacidad persuasiva (Núñez-López, Ávila-Palet \& Olivares-Olivares, 2018). Ello comporta: obtener información, gestionar, generar y difundir conocimiento. Además, de ser un recurso que articula procesos metodológicos en la formación.

Cabría preguntarse cómo afecta a nuestros estudiantes de magisterio la irrupción de las tecnologías en la formación y aprendizaje de los mismos, así como el hecho de que sean o no capaces de desenvolverse con ellas (Snell-Siddle, Snell \& Fisher, 2017). Desde 1998 Tapscott utilizó, por primera vez, la expresión "Generación NET", desde entonces han surgido numerosas definiciones o términos que denominan a los individuos nacidos después de 1982 (considerada la primera generación que ha crecido en un entorno completamente tecnológico) y, según diversos autores como Gasser \& Palfrey (2008) estas generaciones poseen unas características diferentes a las de las generaciones anteriores y características comunes entre ellos mismos (Pedró, 2009). Posteriormente surgieron denominaciones como "inmigrantes digitales", donde no solo se diferencian los estudiantes en su forma de vestir o de hablar, sino en su forma de procesar la información y a estos nuevos estudiantes se les denomina "nativos digitales", que se caracterizan porque su lenguaje es el digital pero el sistema educativo no fue diseñado para ellos, lo que conlleva repercusiones en el sistema de formación de Educación Superior, razón por la que los docentes deben aprender a trabajar con un lenguaje digital, que no es el suyo y deben reconsiderar las metodologías y el contenido a desarrollar en las aulas en función de los nuevos recursos que tienen a su disposición. La cuestión no es que las metodologías cambian en la medida que se utilizan, sino que se articulan y adicionan a nuevos métodos que se pueden llevar a cabo mediante recursos y materiales de esta naturaleza.

Pero la formación de los futuros docentes no puede quedar reducida a la mera adquisición de destrezas tecnológicas, que siendo necesarias, debe transcender y abordar la aplicación didáctica de las mismas (Apple, 2018). Ello supone que los futuros docentes deben planificar, llevar a cabo procesos didácticos, tutorizar, etc. Son todas ellas acciones y procesos en las que la competencia digital es necesaria para gestionar los recursos digitales, aunque frecuentemente, las evidencias ponen de manifiesto que el nivel de fracaso en la gestión de los cursos en línea es elevado, superando el 60\%.

El avance hacia el nuevo rol docente urge a profundizar en la selección, organización y distribución de los recursos de información que proporciona la propia red. La competencia comunicativa y digital surgen de la integración de entornos virtuales y personales (Salinas, De Benito \& Lizana, 2014), que deben conducir hacia un Humanismo cívico. Dicho lo cual, la alfabetización digital, considerada en su más amplia realidad, integra todas las competencias que un futuro maestro necesita para desenvolverse de modo efectivo en la sociedad de la información y el conocimiento (García-Ávila, 2017).

En este sentido se orienta la definición sobre competencia digital que aporta la Comisión Europea (European Parlament and the Council, 2006), que define la competencia digital como "el uso seguro y crítico de las tecnologías de la sociedad de la información para el trabajo, el ocio y la comunicación", que se manifiesta en la utilización de ordenadores para evaluar, guardar e intercambiar información, entre otros aspectos, así como participar en redes de colaboración a través de Internet. Atendiendo a ello, se asume la alfabetización digital, que comprende el uso adecuado de la tecnología, la comprensión crítica de la información y la creación y comunicación de contenido digital que, relacionados con la competencia comunicativa, constituyen la base para aplicarlos al desempeño didáctico. 
Con todo, el presente estudio pretende arrojar luz en torno a los siguientes objetivos:

- Identificar el nivel de competencia digital del estudiante universitario al inicio de su formación como futuro maestro o maestra.

- Comprender las necesidades de formación digital del estudiante en cuestión en coherencia con su futuro desempeño profesional.

Fines de investigación que parten de la hipótesis de que el estudiante universitario digital, objeto de estudio, (como representantes de la generación de nativos y nativas digitales) muestra un desempeño de la competencia digital heterogéneo y carente en función al dominio de las subcompetencias que la definen (navegación y resolución de problemas técnicos, disposiciones legales reguladoras de los derechos de autor, desarrollo, integración y estructuración de contenidos e interacción a través de medios digitales y gestión de la identidad digital).

Por lo expuesto es relevante describir en la revisión de la literatura las cuatro dimensiones surgida del análisis factorial, que conforman 4 subcompetencias integradas por diferentes variables que correlacionan en torno a una misma dimensión, y aunque responde a una realidad epistemológicamente contextualizada, tienen como referente al Institute for Prospective Technological Studies (IPTS), uno de los centros de investigación de la Comisión Europea, y responden a los resultados del Proyecto DIGCOMP (Ferrari, 2013), así como el "Proyecto Marco común de competencia digital docente" del Instituto Nacional de Tecnologías Educativas y de Formación del Profesorado (2017). Se definen cuatro subcompetencias: "navegación y resolución de problemas técnicos", "disposiciones legales reguladoras de los derechos de autor", "desarrollo, integración y estructuración de contenidos" e "interacción a través de medios digitales y gestión de la identidad digital" (Cabero-Almenara \& Llorente-Cejudo, 2008).

\section{La competencia digital desde una visión holística}

El Marco Común de Competencia Digital Docente (INTEF, 2017) ofrece una visión amplia de la complejidad que entrańa el aprendizaje de la competencia digital, estableciendo una estructura general que incluye las diferentes áreas o subcompetencias que precisa la figura docente actual.

La subcompetencia "navegación y resolución de problemas técnicos”, alude a la habilidad para identificar necesidades y recursos digitales, tomar decisiones a la hora de elegir la "herramienta" digital apropiada, acorde a la finalidad o necesidad y resolver problemas (Aranda, Martínez, Faraci \& Cechich, 2013). Podemos considerar esta área, junto con la de seguridad, las dos áreas que son transversales a las áreas de la Información, la Comunicación y la Creación de contenidos. La resolución de problemas técnicos alude a las siguientes unidades de competencia:

- Resolución de problemas técnicos a través de su identificación.

- Identificación de necesidades y respuestas tecnológicas: uso de recursos, herramientas...

- Innovación y uso de la tecnología digital de forma creativa.

- Identificación de lagunas en la competencia digital.

La seguridad como protección de información y datos personales se encuentra muy ligada al dominio instrumental para poder llevar a cabo las medidas correctas de protección (Solarte, Enriquez \& Benavides, 2015). Y lo mismo ocurre con la transversalidad de la competencia en resolución de problemas en lo relacionado con la navegación, que permite buscar información digital en red, aspectos que han sido detectados como elementos de mejora en la formación de los estudiantes de primer curso del grado de maestros y maestras (Castellanos, Sánchez-Romero y Calderero, 2017; Napal, Peñalva.Vélez \& Mendióroz, 2018). Otros estudios valoran las competencias técnicas que tienen los futuros docentes (Tondeur et al., 2015), que se definen como la combinación de habilidades técnico-procesales, cognitivas y socio-emocionales, necesarias para vivir, aprender y trabajar en la sociedad digital (Fraser, Atkins \& Richard, 2013; Nawaz \& Kundi, 2010; Eshet-Alkalai, 2012).

Especial relevancia adquiere la subcompetencia "disposiciones legales reguladoras de los derechos de autor y licencias de uso". Los derechos de au- 
tor responden a uno de los aspectos más interesantes de la propiedad intelectual, en la medida que aportan soluciones a posibles conflictos que pudieran surgir en las relaciones entre autores, los editores y usuarios. Se considera relevante que los estudiantes muestren interés por su conocimiento; en aspectos relativas al conocimiento de los procedimientos por los cuales se puede liberalizar su obra o hacerla de dominio público, así como una preocupación por cumplir las normas legales cuando emite o recibe mensajes digitales ( $\mathrm{Ra}$ mírez \& Arellano, 2015).

La tercera subcompetencia es de vital importancia debido a que se vincula con otras subcompetencias de la competencia comunicativa, tales como la morfosintáctica, el registro lingüístico o la sociolingüística, en concreto se hace referencia al "desarrollo, integración y estructuración de contenidos", de vital importancia para la construcción del discurso didáctico. La subcompetencia de referencia permite elaborar materiales dedicados a la formación de futuros profesionales de la educación, atendiendo a diferentes ámbitos de la tecnología educativa, así como a la formación de futuros profesionales de la educación (Cabero, Marín-Díaz e Infante, 2011). Facilitar esa formación, es oportuno poner a disposición de los profesionales y futuros profesionales de la educación un entorno formativo telemático para la adquisición de diferentes capacidades y competencias que permitan la utilización de las TIC.

En diferentes investigaciones se ha estudiado, no solo las carencias que tienen los estudiantes respecto a la unidad de competencia "desarrollo, integración y estructuración de contenidos", a fin de poder gestionar la competencia digital en contextos educativos, sino también el "hándicap" inicial que supone el desconocimiento de principios elementales de la ciencia didáctica en el primer año en el que se cursa la carrera (Colomer, Saiz \& Bel, 2018). De modo que la mejora de la competencia digital precisa del desarrollo de las habilidades de pensamiento de orden superior que son habitualmente relegadas a un segundo plano de actuación.

Con todo y a pesar de las evidencias científicas que demuestra la potencialidad de los contenidos digitales educativos, es necesario "reajustar el sentido de la formación para los mismos en la misma dirección del desarrollo profesional, tanto a través de la formación inicial como la formación continua para su logro" (Tejada \& Pozos, 2018, p. 28).

En último lugar, se aborda la "interacción a través de medios digitales y gestión de la identidad digital", subcompetencia "que permite definir nuevos escenarios, entornos y posibilidades para la educación, formación profesional y capacitación laboral" (Velázquez-Sortino, Gómez-Zermeño \& Alemán de la Garza, 2017, p. 151).

Las posibilidades de la metodología didáctica aconsejan que los futuros maestros aprendan a utilizar "herramientas" digitales distintas para interactuar con los demás, como el correo electrónico, WhatsApp, redes sociales, etc., que incremente el potencial de uso de las TIC en el ámbito educativo, interacción que compromete a cuidar la imagen en línea de quienes utilizan los recursos telemáticos y la identidad digital, en la medida que la interacción digital favorece el incremento considerable de datos personales en el entorno digital, coincidiendo, o no, la identidad personal con la analogía (Giones-Valls \& Serrat-Brustenga, 2010).

Los datos que compartimos en los medios, en las redes digitales, condicionan nuestra vida e incluso nuestra vida social y laboral. Esta subcompetencia integra la capacidad de los estudiantes de trabajar en entornos virtuales y personales, en aspectos como utilizar herramientas digitales diferentes para interactuar, que abordan en el ámbito de la Didáctica el conocimiento de las interacciones que ha de establecerse entre diferentes fuentes de información digitales, atendiendo a la actividad docente que ha de planificar.

\section{Materiales Y Métodos}

\section{Participantes}

El presente estudio estuvo conformado por una población de 559 estudiantes. Los criterios de inclusión para participar en el estudio era pertenecer a las universidades de Granada, Jaén y Oviedo, así como ser estudiante de primer curso del 
título de Grado de Educación Primaria. Se parte de una población inicial de mil cuatrocientos treinta estudiantes, siendo la muestra mínima representativa de 304 estudiantes, según la fórmula "Sample Size Calculator for a proportion (absolute margin). El perfil de la población participante se concreta en torno a la siguiente información:

Tabla 1

Distribución de la muestra

\begin{tabular}{|c|c|c|c|}
\hline Ítem & Elección & $\begin{array}{l}\text { Núme- } \\
\text { ro }\end{array}$ & $\%$ \\
\hline \multirow[t]{3}{*}{$\begin{array}{l}\text { Universidad de } \\
\text { procedencia }\end{array}$} & $\begin{array}{l}\text { Universidad de } \\
\text { Granada }\end{array}$ & 65 & 11.6 \\
\hline & Universidad de Jaén & 297 & 53.1 \\
\hline & Universidad de Oviedo & 197 & 35.2 \\
\hline \multirow[t]{2}{*}{ Sexo } & Mujeres & 424 & 75.8 \\
\hline & Hombre & 135 & 24.2 \\
\hline \multirow{3}{*}{$\begin{array}{l}\text { Estudios de Bachi- } \\
\text { llerato o Formación } \\
\text { Profesional }\end{array}$} & Centro público & 463 & 82.8 \\
\hline & Centro concertado & 62 & 11.11 \\
\hline & Centro privado & 34 & 6.1 \\
\hline \multirow{7}{*}{$\begin{array}{l}\text { Titulación } \\
\text { académica de los } \\
\text { padres, madres o } \\
\text { tutores legales }\end{array}$} & Educación Primaria & 176 & 31.5 \\
\hline & Bachillerato & 103 & 18.4 \\
\hline & Formación Profesional & 152 & 27.2 \\
\hline & Diplomatura & 19 & 3.4 \\
\hline & Licenciatura & 91 & 16.3 \\
\hline & Maestría & 11 & 2 \\
\hline & Doctorado & 7 & 1.3 \\
\hline \multirow{2}{*}{$\begin{array}{l}\text { Titulación previa a } \\
\text { Magisterio }\end{array}$} & Sí & 113 & 20.2 \\
\hline & No & 446 & 79.8 \\
\hline \multirow{2}{*}{$\begin{array}{l}\text { Estudios previos } \\
\text { en un centro ins- } \\
\text { crito al Programa } \\
\text { de Tecnologías de } \\
\text { la Información y la } \\
\text { Comunicación }\end{array}$} & Sí & 361 & 64.6 \\
\hline & No & 198 & 35.4 \\
\hline \multirow[t]{5}{*}{$\begin{array}{l}\text { Destreza tecno- } \\
\text { lógica }\end{array}$} & $\begin{array}{l}\text { Aprendizaje en la } \\
\text { familia }\end{array}$ & 49 & 8.8 \\
\hline & $\begin{array}{l}\text { Aprendizaje en el } \\
\text { centro que estudió }\end{array}$ & 111 & 19.9 \\
\hline & $\begin{array}{l}\text { Aprendizaje en otras } \\
\text { instituciones }\end{array}$ & 32 & 5.7 \\
\hline & Autoaprendizaje & 361 & 64.6 \\
\hline & Otros & 6 & 1.1 \\
\hline \multirow{2}{*}{$\begin{array}{l}\text { Formación especí- } \\
\text { fica previa en TIC }\end{array}$} & Sí & 253 & 45.3 \\
\hline & No & 306 & 54.7 \\
\hline \multirow{2}{*}{$\begin{array}{l}\text { Modalidad de la } \\
\text { formación TIC } \\
\text { recibida }\end{array}$} & Presencial & 347 & 62.1 \\
\hline & Virtual & 206 & 36.9 \\
\hline
\end{tabular}

Elaboración propia (2019)

\section{Instrumento}

La investigación ha utilizado un instrumento de medida "ad hoc" con escalas aditivas tipo Likert, consistente en 51 ítems sobre los rasgos de la competencia digital. Las opciones de respuesta utilizadas han sido: "Nunca=1", "Casi nunca=2", "En algunas ocasiones=3", "Casi siempre $=4$ ", "Siempre=5" y "No sabe/No contesta".

La fiabilidad del instrumento se realizó mediante el Alfa de Cronbach respecto a la totalidad de la escala es de 0.791. La eliminación de cada ítem respecto a la totalidad, aporta los siguientes datos (ítem no $33=0.770<0.789=1$ tem no 22 ). No se suprime ningún ítem, ya que al eliminar respectivamente cada uno de los ítems, el resultado no aporta un alfa superior al de la totalidad de la escala; es decir 0.791. Se aplica el alfa de las dos mitades para conocer el nivel de consistencia entre las dos partes del cuestionario; en los ítems impares se obtuvo un alfa $=0.6785$; en los ítems pares un alfa $=0.740$; por consiguiente, hay una consistencia razonable en la fiabilidad de los ítems pares respecto a los impares.

En la validez de constructo se utilizan los mismos procedimientos estadísticos que en la validez del cuestionario de competenciales digitales, con resultados mostrados en la tabla 2 . La medida de adecuación muestral aporta un KMO 0.867, mientras que la prueba de esfericidad de Bartlett confirma la existencia de factores subyacentes en la matriz de datos, siendo $\alpha=0.000$ y el índice de discriminación de 0.5 , partiendo para realizar la validez de constructo de 51 ítems. La solución del análisis factorial, define 4 factores, que integran 21 de los ítems originalmente propuestos (tabla 3) explicativos del $41.316 \%$ de la varianza, con un índice mínimo de discriminación de 0.5.

Tabla 2

Resumen estadístico del análisis factorial-competencia digital.

\begin{tabular}{llc}
\hline $\begin{array}{c}\text { Medida de adecuación } \\
\text { muestral }\end{array}$ & \multicolumn{1}{c}{$\begin{array}{c}\text { Kaiser.Meyer-Ol- } \\
\text { kin }\end{array}$} & 0.867 \\
\hline Prueba de esfericidad & Chi- cuadrado & 7260.477 \\
de Bartlett & Gl. & 1275 \\
& Sig. & 0.000 \\
\hline
\end{tabular}

Elaboración propia (2019) 
Tabla 3

Varianza explicada y agrupación de los ítems en factores (rotación varimax) - competencia digital.

\begin{tabular}{|c|c|c|}
\hline Factores & $\begin{array}{l}\text { Varianza expli- } \\
\text { cada por factor } \\
\text { (\%) }\end{array}$ & $\begin{array}{l}\text { Ítem que inte- } \\
\text { gran cada factor }\end{array}$ \\
\hline $\begin{array}{l}\text { F-1:Subcompetencia, } \\
\text { navegación y resolución } \\
\text { de problemas técnicos }\end{array}$ & 16.978 & $\begin{array}{l}1,10,37,38,44 \\
45,47\end{array}$ \\
\hline $\begin{array}{l}\text { F-2:Subcompetencia, } \\
\text { disposiciones legales } \\
\text { reguladoras de los } \\
\text { derechos de autor y de } \\
\text { las licencias de uso. }\end{array}$ & 15.508 & $\begin{array}{l}14,21,22,23 \\
33,34,35\end{array}$ \\
\hline $\begin{array}{l}\text { F-3:Subcompetencia,- } \\
\text { desarrollo, integración } \\
\text { y estructuración de } \\
\text { contenidos }\end{array}$ & 5.031 & $27,29,31,32$ \\
\hline $\begin{array}{l}\text { F-4: Subcompetencia, } \\
\text { interacción a través } \\
\text { de medios digitales y } \\
\text { gestión de la identidad } \\
\text { digital. }\end{array}$ & 3.799 & $12,13,24$ \\
\hline Varianza total explicada & 41.316 & \\
\hline Número de factores & 4 & \\
\hline
\end{tabular}

Elaboración propia (2019)

Tipo y diseño de estudio

Se aplica el cuestionario "ad hoc" diseñado desde una metodología de corte cuantitativo con un análisis descriptivo dentro de un estudio más amplio pretest-postest que evalúe la aplicación de un programa formativo a medida, tal y como aplican e investigan otros autores y autoras como González, Román \& Prendes (2018).

\section{Confidencialidad}

El grupo de estudiantes participa de forma voluntaria, garantizándose la protección de la identidad de la población de estudio respeto a sus derechos individuales.

\section{Procedimiento}

El presente trabajo se redacta a partir de las fases I, II, III y IV del proyecto I+D+i del que nace. Siendo la estructura general de las fases del proyecto las que se detallan a continuación:
Fase I: Determinación de los grupos de estudiantes participantes en la investigación.

Fase II: Diagnóstico preliminar de las necesidades formativas: Análisis y valoración de los programas ordinarios de formación en los grupos docentes relacionados con las competencias clave del estudio y las muestras de estudiantes seleccionadas.

Fase III: Construcción y validación del instrumento de evaluación: cuestionario ad hoc.

Fase IV: Aplicación del pretest.

Fase V: Diseño y validación de un programa formativo en línea

Fase VI: Aplicación y evaluación del programa formativo.

Fase VII: Aplicación del postest.

\section{Resultados}

La presentación y análisis de los resultados se disponen en torno a la estructura del cuestionario de competencia digital diseñado en coherencia con las subcompetencias digitales de estudio ya explicitadas. De modo que la información se organiza alrededor de los siguientes apartados, aglutinando y relacionando los desempeños que los componen (tabla 4):

\section{Tabla 4}

Desempeños que componen las subcompetencias de la competencia digital.

\begin{tabular}{|c|c|}
\hline Elección & Número \\
\hline \multirow[t]{3}{*}{$\begin{array}{l}\text { Acceso a la } \\
\text { información }\end{array}$} & $\begin{array}{l}\text { Navegación, búsqueda y filtrado de informa- } \\
\text { ción. }\end{array}$ \\
\hline & Evaluación de la información. \\
\hline & $\begin{array}{l}\text { Almacenamiento y recuperación de informa- } \\
\text { ción. }\end{array}$ \\
\hline \multirow{6}{*}{$\begin{array}{l}\text { Comunica- } \\
\text { ción }\end{array}$} & Interacción a través de medios digitales \\
\hline & Compartir información y contenidos \\
\hline & Participación ciudadana en línea \\
\hline & Colaboración mediante medios digitales \\
\hline & Netiqueta. \\
\hline & Gestión de la identidad digital. \\
\hline \multirow{4}{*}{$\begin{array}{l}\text { Creación } \\
\text { de conteni- } \\
\text { dos }\end{array}$} & Desarrollo de contenidos. \\
\hline & Integración y reestructuración de contenidos. \\
\hline & Derechos de autor y licencias. \\
\hline & Programación. \\
\hline
\end{tabular}




\begin{tabular}{|c|c|}
\hline Elección & Número \\
\hline \multirow[t]{4}{*}{ Seguridad } & Protección de dispositivos. \\
\hline & $\begin{array}{l}\text { Protección de datos personales e identidad } \\
\text { digital. }\end{array}$ \\
\hline & Protección de la salud. \\
\hline & Protección del entorno. \\
\hline \multirow{4}{*}{$\begin{array}{l}\text { Resolución } \\
\text { de proble- } \\
\text { mas }\end{array}$} & Resolución de problemas técnicos. \\
\hline & $\begin{array}{l}\text { Identificación de necesidades y respuestas } \\
\text { tecnológicas. }\end{array}$ \\
\hline & $\begin{array}{l}\text { Innovación y uso de la tecnología de forma } \\
\text { creativa. }\end{array}$ \\
\hline & $\begin{array}{l}\text { Identificación de lagunas en la competencia } \\
\text { digital. }\end{array}$ \\
\hline
\end{tabular}

Elaboración propia (2019)

\section{El acceso a la información}

El estudiantado universitario digital que forma parte de la presente investigación dista de tener una competencia digital efectiva en términos de acceso a la información. Por un lado, se observa que las habilidades a nivel técnico relacionadas con el almacenamiento y la recuperación de la información tienen una tendencia mayoritaria positiva. De manera que en las respuestas de los ítems de la Tabla 5 visualiza una tendencia general a poner en prácticas estas actividades de manera habitual en su mayoría.

Tabla 5

Competencia digital efectiva en términos de acceso a la información (\%).

\begin{tabular}{lccc}
\hline & $\begin{array}{c}\text { Nunca } \\
\text { o casi } \\
\text { nunca }\end{array}$ & $\begin{array}{c}\text { En } \\
\text { algunas } \\
\text { ocasio- } \\
\text { nes }\end{array}$ & $\begin{array}{c}\text { Casi } \\
\text { siempre } \\
\text { o siem- } \\
\text { pre }\end{array}$ \\
\hline $\begin{array}{l}\text { Guardas información en di- } \\
\text { ferentes formatos clasificán- } \\
\text { dola de forma que la puedas } \\
\text { recuperar fácilmente }\end{array}$ & 11.8 & 23.3 & 64.6 \\
$\begin{array}{l}\text { Realizas copias de seguri- } \\
\text { dad de la información que } \\
\text { consideras relevante }\end{array}$ & 26 & 21.1 & 51.9 \\
$\begin{array}{l}\text { Utilizas espacios de almace- } \\
\text { namiento externo con ese fin }\end{array}$ & 20.8 & 23.8 & 52.2 \\
\hline
\end{tabular}

Elaboración propia (2019)

Sin embargo, los datos informan de un bajo desempeño a nivel de la evaluación y la gestión de la información. Las acciones de evaluación en la Tabla 6 muestran que el acceso crítico a la información no se sitúa en una posición prioritaria a la hora de acceder a la misma.

\section{Tabla 6}

Evaluación y la gestión de la información (\%).

\begin{tabular}{lccc}
\hline & $\begin{array}{c}\text { Nunca } \\
\text { o casi } \\
\text { nunca }\end{array}$ & $\begin{array}{c}\text { En } \\
\text { algunas } \\
\text { ocasio- } \\
\text { nes }\end{array}$ & $\begin{array}{c}\text { Casi } \\
\text { siempre } \\
\text { o siem- } \\
\text { pre }\end{array}$ \\
\hline $\begin{array}{l}\text { Tienes en cuenta las } \\
\text { restricciones de los recursos } \\
\text { educativos publicados con } \\
\text { derechos de autor }\end{array}$ & 38.1 & 23.4 & 29.7 \\
$\begin{array}{l}\text { Utilizas recursos educativos } \\
\text { disponibles en Internet en } \\
\text { función de las demandas que } \\
\text { te plantean las asignaturas }\end{array}$ & 8.4 & 40.3 & 48.2 \\
$\begin{array}{l}\text { Evalúas críticamente la } \\
\text { información que localizas } \\
\text { en Internet posicionándote } \\
\text { sobre su enfoque }\end{array}$ & 20.5 & 37.9 & 39.9 \\
\hline
\end{tabular}

Elaboración propia (2019)

La gestión de la navegación, la búsqueda y el filtrado de la información son desempeńos poco asimilados en la población participante (Tabla 7):

\section{Tabla 7}

Gestión de la navegación, la búsqueda y el filtrado de la información (\%).

\begin{tabular}{lccc}
\hline & $\begin{array}{c}\text { Nunca } \\
\text { o casi } \\
\text { nunca }\end{array}$ & $\begin{array}{c}\text { En } \\
\text { algunas } \\
\text { ocasio- } \\
\text { nes }\end{array}$ & $\begin{array}{c}\text { Casi } \\
\text { siempre } \\
\text { o siem- } \\
\text { pre }\end{array}$ \\
\hline $\begin{array}{l}\text { Configuras el navegador web } \\
\text { de tu ordenador cuando lo } \\
\text { consideras necesario }\end{array}$ & 41.5 & 27 & 26.6 \\
$\begin{array}{l}\text { Seleccionas fuentes de infor- } \\
\text { mación de interés profesional }\end{array}$ & 24.3 & 47.6 & 26.4 \\
$\begin{array}{l}\text { Localizas información digi- } \\
\text { talizada utilizando palabras } \\
\text { clave y filtros para ajustar y } \\
\text { limitar tu búsqueda }\end{array}$ & 27.4 & 28.1 & 42.5 \\
$\begin{array}{l}\text { Usas distintos buscadores } \\
\text { para localizar información y } \\
\text { recursos }\end{array}$ & 37.2 & 23.1 & 39.5 \\
\hline
\end{tabular}

Elaboración propia (2019) 


\section{La comunicación}

La participación en línea y la interacción a través de los medios digitales son acciones que, popularmente, se presuponen intrínsecas a la propia idiosincrasia de los nativos y las nativas digitales.

En este sentido, el análisis de la información arroja un apoyo claro a esta premisa a través de los siguientes resultados:

\section{Tabla 8}

Participación en línea y la interacción a través de los medios digitales $(\%)$.

\begin{tabular}{lccc}
\hline & $\begin{array}{c}\text { Nunca o casi } \\
\text { nunca }\end{array}$ & $\begin{array}{c}\text { En } \\
\text { algunas } \\
\text { ocasio- } \\
\text { nes }\end{array}$ & $\begin{array}{c}\text { Casi } \\
\text { siempre } \\
\text { o siem- } \\
\text { pre }\end{array}$ \\
\hline $\begin{array}{l}\text { Utilizas al menos tres } \\
\text { herramientas digitales } \\
\text { distintas para interactuar } \\
\text { con los demás }\end{array}$ & 0.7 & 8.4 & 90.7 \\
$\begin{array}{l}\text { Cuando navegas, inte- } \\
\text { raccionas con diferentes } \\
\text { fuentes de información } \\
\text { digital }\end{array}$ & 5 & 19.1 & 76.4 \\
$\begin{array}{l}\text { Participas activamen- } \\
\text { te en al menos dos } \\
\text { comunidades virtuales y } \\
\text { redes sociales }\end{array}$ & & & \\
$\begin{array}{l}\text { Aprovechas las posibi- } \\
\text { lidades que te ofrecen } \\
\text { los medios digitales } \\
\text { incluyendo a las redes } \\
\text { sociales para promover } \\
\text { la participación social de } \\
\text { la ciudadanía }\end{array}$ & & & \\
\hline
\end{tabular}

Elaboración propia (2019)

Aunque en la mayoría de los ítems hay un alto porcentaje de la población que siempre o casi siempre participa e interacciona de forma activa en línea, el uso concreto de la red para la participación social de la ciudadanía no es una actividad que se practique con tanta frecuencia; infiriéndose así que el perfil de estudiantes digital se identifica de forma clara con la presencia y la participación digital pero no tan nítidamente con el uso crítico y social del medio.

En la línea de la inferencia anterior, se observa que el desempeńo relacionado con compartir información y colaborar mediante medios digitales presenta carencias significativas en el estudiante digital ( Tabla 9).

Tabla 9

Compartir información y colaborar mediante medios digitales (\%).

\begin{tabular}{|c|c|c|c|}
\hline & $\begin{array}{l}\text { Nunca o casi } \\
\text { nunca }\end{array}$ & $\begin{array}{l}\text { En } \\
\text { algunas } \\
\text { ocasio- } \\
\text { nes }\end{array}$ & $\begin{array}{l}\text { Casi } \\
\text { siempre } \\
\text { o siem- } \\
\text { pre }\end{array}$ \\
\hline $\begin{array}{l}\text { Cuando compartes in- } \\
\text { formación o contenidos } \\
\text { obtenidos en línea, citas } \\
\text { al autor y a la fuente, } \\
\text { siguiendo las normas } \\
\text { existentes }\end{array}$ & 31.8 & 33.3 & 32.5 \\
\hline $\begin{array}{l}\text { Seleccionas para com- } \\
\text { partir en red, noticias y } \\
\text { recursos localizados en } \\
\text { diversas páginas web, } \\
\text { foros y otras comunida- } \\
\text { des en línea }\end{array}$ & 33 & 35.2 & 30 \\
\hline $\begin{array}{l}\text { Utilizas programas y } \\
\text { aplicaciones para crear } \\
\text { presentaciones digitales } \\
\text { proyectables }\end{array}$ & 31.3 & 28.6 & 37.8 \\
\hline $\begin{array}{l}\text { Difundes en línea las } \\
\text { presentaciones digitales } \\
\text { creadas a través de } \\
\text { envío por correo, redes } \\
\text { sociales, subida a repo- } \\
\text { sitorios, etc }\end{array}$ & 48.3 & 28.1 & 18.8 \\
\hline $\begin{array}{l}\text { Usas herramientas de } \\
\text { trabajo colaborativo en } \\
\text { línea para crear conoci- } \\
\text { miento compartido }\end{array}$ & 32.6 & 40.8 & 32.7 \\
\hline
\end{tabular}

Elaboración propia (2019)

El análisis de las normas de comportamiento a través de Internet (netiqueta) muestra que la consulta de las disposiciones legales que regulan los derechos y los deberes de quienes emitimos y recibimos mensajes digitales no suele ser una actividad que se tenga presente en la comunicación en línea del estudiante digital, "nunca o casi nunca" $65.5 \%$.

Así mismo, aunque los porcentajes sean algo más alentadores, el resto de ítems relacionados no resuelven un desempeño generalizado de esta unidad competencial (Tabla 10). 


\section{Tabla 10}

Disposiciones legales que regulan los derechos y los deberes $(\%)$.

\begin{tabular}{lccc}
\hline & $\begin{array}{c}\text { Nunca } \\
\text { o casi } \\
\text { nunca }\end{array}$ & $\begin{array}{c}\text { En } \\
\text { algunas } \\
\text { ocasio- } \\
\text { nes }\end{array}$ & $\begin{array}{c}\text { Casi } \\
\text { siempre } \\
\text { o siem- } \\
\text { pre }\end{array}$ \\
\hline $\begin{array}{l}\text { La consulta de las disposicio- } \\
\text { nes legales que regulan los } \\
\text { derechos y los deberes de }\end{array}$ & 65.5 & 17.4 & 10.2 \\
quienes emitimos y recibimos & & & \\
mensajes digitales & & & \\
$\begin{array}{l}\text { Cuando emites y recibes } \\
\text { mensajes digitales cumples }\end{array}$ & 24.9 & 25.6 & 32.3 \\
las normas legales que & & & \\
regulan tal transferencia de & & & \\
información \\
$\begin{array}{l}\text { Tienes presente las carac- } \\
\text { terísticas socioculturales de }\end{array}$ \\
las audiencias hacia los que \\
diriges tus mensajes digitales \\
que creas para difundirlos a \\
través de internet
\end{tabular}

Elaboración propia (2019)

La gestión de la identidad digital en torno a las interacciones y participación en el medio muestra que un $79.8 \%$ cuida la información que se hace pública "casi siempre o siempre". Sin embargo, el acto de revisión que precisa la gestión de la identidad digital no se completa en un alto porcentaje del estudiante digital, observándose que el rastreo de la huella digital en Internet no es un proceso primordialmente asumido (Tabla 11).

Tabla 11

Gestión de la identidad digital (\%).

\begin{tabular}{lccc}
\hline & $\begin{array}{c}\text { Nunca } \\
\text { o casi } \\
\text { nunca }\end{array}$ & $\begin{array}{c}\text { En } \\
\text { algunas } \\
\text { ocasio- } \\
\text { nes }\end{array}$ & $\begin{array}{c}\text { Casi } \\
\text { siempre } \\
\text { o siem- } \\
\text { pre }\end{array}$ \\
\hline $\begin{array}{l}\text { Gestión de la identidad digital } \\
\text { que se realiza en torno a las } \\
\text { interacciones y participación } \\
\text { en el medio } \\
\text { Gestión de la identidad digital }\end{array}$ & 5 & 14.3 & 79.8 \\
\hline
\end{tabular}

Elaboración propia (2019)

\section{Creación de contenidos}

El perfil de estudiante digital generalizado infunde una visión de competencia creativa de material digital prácticamente intrínseca a la participación en el medio. Sin embargo, el análisis de los resultados obtenidos muestra que la creación de audios digitales mezclando voz y música además de la creación de vídeos propios insertando fotografías, gráficos, fragmentos de películas y textos tienen un desempeño bajo en un amplio número de participantes. En sincronía con los análisis anteriores, se observa que el uso de programas de edición digital para modificar contenidos propios o ajenos es un desempeńo poco asumido por la mayoría de los estudiantes. Incluso la creación de presentaciones digitales combinando imágenes, gráficos y textos presenta un porcentaje inferior a la mitad de personas que lo valoran como una actividad que siempre o casi siempre realizan, como se presenta en la Tabla 12

Tabla 12

Competencia creativa de material digital(\%).

\begin{tabular}{lccc}
\hline & $\begin{array}{c}\text { Nunca o casi } \\
\text { nunca }\end{array}$ & $\begin{array}{c}\text { En } \\
\text { algunas } \\
\text { ocasio- } \\
\text { nes }\end{array}$ & $\begin{array}{c}\text { Casi } \\
\text { siempre } \\
\text { o siem- } \\
\text { pre }\end{array}$ \\
\hline $\begin{array}{l}\text { La creación de audios } \\
\text { digitales mezclando voz } \\
\text { y música }\end{array}$ & 63.4 & 21.1 & 12.9 \\
$\begin{array}{l}\text { La creación de vídeos } \\
\text { propios insertando } \\
\text { fotografías, gráficos, } \\
\text { fragmentos de películas } \\
\text { y textos }\end{array}$ & 45.8 & 28.6 & 24.2 \\
$\begin{array}{l}\text { El uso de programas } \\
\text { de edición digital para } \\
\text { modificar contenidos } \\
\text { propios o ajenos } \\
\text { Creación de presen- } \\
\text { taciones digitales } \\
\text { combinando imágenes, } \\
\text { gráficos y textos }\end{array}$ & 49.4 & 27.5 & 20.1 \\
\hline
\end{tabular}

Elaboración propia (2019)

El desempeño que más carencias presenta es el referente al conocimiento, valoración y aplicación de los derechos de autor y las licencias en la creación, integración, reestructuración y gestión de materiales en línea (Tabla 13).

\section{Tabla 13}

Conocimiento, valoración y aplicación de los derechos de autor $(\%)$. 


\begin{tabular}{lccc}
\hline & $\begin{array}{c}\text { Nunca } \\
\text { o casi } \\
\text { nunca }\end{array}$ & $\begin{array}{c}\text { En } \\
\text { algunas } \\
\text { ocasio- } \\
\text { nes }\end{array}$ & $\begin{array}{c}\text { Casi } \\
\text { siempre } \\
\text { o siem- } \\
\text { pre }\end{array}$ \\
\hline $\begin{array}{l}\text { Te preocupas de conocer las } \\
\text { normativas que regulan los } \\
\text { derechos de autor según el } \\
\text { tipo de licencia elegida para }\end{array}$ & 60.5 & 19.9 & 15.2 \\
protegerlos & & & \\
$\begin{array}{l}\text { Respetas las obligaciones } \\
\text { y derechos previstos en }\end{array}$ & 32.7 & 25.2 & 30.4 \\
$\begin{array}{l}\text { las normativas que regulan } \\
\text { las licencias de uso de los } \\
\text { materiales creados por los } \\
\text { autores }\end{array}$ & & & \\
$\begin{array}{l}\text { Te preocupas por conocer los } \\
\text { procedimientos por los cua- } \\
\text { les un autor puede liberalizar } \\
\text { sus derechos para hacer su } \\
\text { obra de dominio público y } \\
\text { gratuito }\end{array}$ & & & \\
\hline
\end{tabular}

Elaboración propia (2019)

\section{Seguridad}

Se observa una visión positiva del desempeño de acciones para proteger la seguridad en línea en términos de protección de dispositivos y de datos personales e identidad digital. El perfil de estudiantes digital (Tabla 14) realiza operaciones básicas de mantenimiento y protección de los dispositivos que utiliza de forma mayoritaria "casi siempre o siempre" $59.4 \%$ y sabe actuar cuando detecta amenazas de seguridad. Es conveniente señalar que un grupo importante no tiene la competencia para autogestionar la protección.

\section{Tabla 14}

Operaciones básicas de mantenimiento y protección de los dispositivos (\%).

\begin{tabular}{lccc}
\hline & $\begin{array}{c}\text { Nunca } \\
\text { o casi } \\
\text { nunca }\end{array}$ & $\begin{array}{c}\text { En } \\
\text { algunas } \\
\text { ocasio- } \\
\text { nes }\end{array}$ & $\begin{array}{c}\text { Casi } \\
\text { siempre } \\
\text { o siem- } \\
\text { pre }\end{array}$ \\
\hline $\begin{array}{l}\text { Realiza operaciones básicas } \\
\text { de mantenimiento y protec- } \\
\text { ción de los dispositivos que } \\
\text { utiliza de forma mayoritaria }\end{array}$ & 10.7 & 28.8 & 59.4 \\
$\begin{array}{l}\text { Sabe actuar cuando detecta } \\
\text { amenazas de seguridad en } \\
\text { sus dispositivos en muchos } \\
\text { casos }\end{array}$ & 26.3 & 25 & 45 \\
\hline
\end{tabular}

Elaboración propia (2019)

La autoprotección de los datos personales, mos- trados en la Tabla 15, se erige como un desempeño mayoritariamente asumido, observándose que se protegen los datos personales sensibles "casi siempre o siempre" $74.6 \%$ y la identidad digital propia y de los demás "casi siempre o siempre" $75.7 \%$.

\section{Tabla 15}

Autoprotección (\%).

\begin{tabular}{lccc}
\hline & $\begin{array}{c}\text { Nunca } \\
\text { o casi } \\
\text { nunca }\end{array}$ & $\begin{array}{c}\text { En } \\
\text { algunas } \\
\text { ocasio- } \\
\text { nes }\end{array}$ & $\begin{array}{c}\text { Casi } \\
\text { siempre } \\
\text { o siem- } \\
\text { pre }\end{array}$ \\
\hline $\begin{array}{l}\text { Autoprotección de los datos } \\
\text { personales }\end{array}$ & 5.4 & 16.6 & 74.6 \\
$\begin{array}{l}\text { La identidad digital propia y } \\
\text { de los demás }\end{array}$ & 5.9 & 16.6 & 75.7 \\
\hline
\end{tabular}

Elaboración propia (2019)

\section{Resolución de problemas}

La autonomía del estudiantes digital en la resolución de problemas técnicos es mayoritariamente baja, observándose que la identificación de problemas técnicos explicando con claridad en qué consiste en mal funcionamiento en cuestión es poco desarrollada "nunca o casi nunca" $41.2 \%$ y que la resolución de los problemas técnicos no complejos relacionados con los dispositivos y el entorno digital habitual con la ayuda manual o la información técnica disponible, tampoco es una acción que se suela abordar de manera generalizada, se muestra en la Tabla 16

\section{Tabla 16}

Resolución de problemas (\%).

\begin{tabular}{lccc}
\hline & $\begin{array}{c}\text { Nunca } \\
\text { o casi } \\
\text { nunca }\end{array}$ & $\begin{array}{c}\text { En } \\
\text { algunas } \\
\text { ocasio- } \\
\text { nes }\end{array}$ & $\begin{array}{c}\text { Casi } \\
\text { siempre } \\
\text { o siem- } \\
\text { pre }\end{array}$ \\
\hline $\begin{array}{l}\text { Identificación de problemas } \\
\text { técnicos explicando con cla- } \\
\text { ridad en qué consiste en mal } \\
\text { funcionamiento en cuestión }\end{array}$ & 41.2 & 30.8 & 22.8 \\
$\begin{array}{l}\text { Resolución de los problemas } \\
\text { técnicos no complejos rela- } \\
\text { cionados con los dispositivos }\end{array}$ & 37.1 & 31.8 & \\
$\begin{array}{l}\text { y el entorno digital habitual } \\
\text { con la ayuda manual o la in- } \\
\text { formación técnica disponible }\end{array}$ & & & \\
\hline
\end{tabular}

Elaboración propia (2019) 
Por su parte, los datos del desempeńo de acciones relacionadas con la resolución de problemas a través del uso de la tecnología de forma creativa y la identificación de lagunas en la competencia digital, muestran que hay un porcentaje alentador de personas que asumen un perfil activo de cambio hacia la mejora.

Tabla 17

Uso de la tecnología de forma creativa (\%).

\begin{tabular}{lccc}
\hline & $\begin{array}{c}\text { Nunca o casi } \\
\text { nunca }\end{array}$ & $\begin{array}{c}\text { En } \\
\text { algunas } \\
\text { ocasio- } \\
\text { nes }\end{array}$ & $\begin{array}{c}\text { Casi } \\
\text { siempre } \\
\text { o siem- } \\
\text { pre }\end{array}$ \\
\hline $\begin{array}{l}\text { Utilizas las tecnolo- } \\
\text { gías en tu actividad }\end{array}$ & 6.4 & 28.1 & 64.6 \\
académica para buscar & & & \\
soluciones alternativas & & & \\
e innovadoras que & & & \\
faciliten las áreas de & & & \\
aprendizaje & & & \\
Utilizas las tecnologías \\
en tu labor diaria para \\
gestionar soluciones \\
innovadoras y participar \\
en proyectos creativos
\end{tabular}

Elaboración propia (2019)

\section{Discusión y Conclusiones}

Los resultados de investigación obtenidos respaldan la hipótesis de trabajo, poniendo de relieve la gran heterogeneidad competencial digital que tiene el estudiante universitario. Aunque se pueden sacar conclusiones que explican la capacidad o falta de la misma para desarrollar la competencia digital en su futura labor como docentes, se observa que el hecho de compartir un momento histórico concreto caracterizado por el predominio de un lenguaje digital, no significa que los maestros y las maestras estén previamente preparados y preparadas para aplicar y valorar la competencia digital en su ideario y práctica docente.

La reflexión en torno a los resultados compartidos permite afirmar que hay una clara tendencia del estudiante digital que presenta un desempeño que implica habilidades de pensamiento de orden inferior, focalizados en el almacenamiento, recuperación, presencia y participación en línea y mantenimiento y protección. Mientras que, por el contrario, las habilidades de orden superior relacionadas con la evaluación y la gestión de la información, el filtrado, la creación y el uso crítico, la valoración de derechos y la autonomía en la resolución de problemas, se aplican con menos asiduidad (González, Cárdenas \& Arellano, 2017; Moreno-Rodríguez, Gabarda \& Rodríguez-Martín, 2016; Rangel, 2018; Torres \& Jaimes, 2015). De manera que, en coherencia con investigaciones previamente citadas dentro del presente artículo, los denominados nativos y nativas digitales no muestran un perfil unificado que incluya una competencia digital efectiva que les permita adaptarse a situaciones y contextos diversos a través de la selección, entendimiento, procesamiento, crítica y transformación de la información digital. Estos datos obtenidos podrían adaptarse a la propuesta establecida por Churches (2009) donde configura y distribuye las habilidades digitales en torno al pensamiento de orden superior e inferior.

Evidenciándose que la incorporación del lenguaje digital y sus aplicaciones no son un factor determinante y definitorio para el necesario cambio hacia el desarrollo y asimilación de habilidades de pensamiento de orden superior dentro de la tradicional taxonomía de Bloom. Siendo necesario que el potencial creativo que se observa en el análisis de los resultados, se oriente más allá de la presencia y la participación superficial en línea, hacia una participación crítica y significativa donde los futuros maestros y maestras se empoderen digitalmente desde la interiorización y práctica de habilidades de pensamiento de orden superior.

Con todo, se estima la concreción de pautas de actuación en torno al empoderamiento y mejora de la competencia digital de los futuros maestros 
y maestras requiere de un proceso longitudinal personalizado, donde se interrelacionan todas las propuestas de manera progresiva:

- Itinerario formativo trasversal de la competencia digital que aborde el desarrollo de los desempeños que implican habilidades de pensamiento de orden superior.

- La formación tiene que ser comprendida como un proceso paulatino que parte de las experiencias, estilos y ritmos de aprendizaje diversos de los diferentes grupos de estudiantes.

- La adquisición de la competencia digital requiere de una práctica constante retroalimentada que cuestiona los modelos tradicionales de enseńanza y sitúa al alumnado en el centro de su propio proceso de aprendizaje. De manera que es necesario tutorizar desde la Universidad el proceso de adquisición de desempeños digitales desde la práctica y la experimentación, desde el aprendizaje del grupo natural y el análisis metacognitivo de la individualidad de cada estudiante.

\section{Agradecimiento}

A la fuente de financiación de la investigación I+$\mathrm{D}+\mathrm{i}$ de donde se extrae la presente información de estudio, denominada: "Evaluación y desarrollo de dos competencias genéricas en estudiantes de primer año del grado de Maestro en Educación Primaria”, con referencia: EDU2015-70491-R".

\section{REFERENCIAS BIBLIOGRÁFICAS}

Apple, M., W. (2018). Curricular form and the logic of technical control: building the possessive individual. En M. W. Apple (editor). Cultural and Economic Reproduction in Education (pp. 8 - 28). London: Routledge.

Aranda, G. A., Martínez, N. Faraci, P. \& Cechich, A. (2013). Hacia un framework de evaluación de calidad de información en foros de discusión técnicos. Argentine Symposium on Software Engineering. Recuperado de http://42jaiio.sadio.org.ar/proceedings/simposios/Trabajos/ASSE/01.pdf

Cabero, J. \& Llorente, M. C. (2008). La alfabetización digital de los alumnos. Competencias digitales para el siglo XXI. Revista Portuguesa de Pedagogía, 36 (1). Recuperado de https://impactum-journals.uc.pt/rppedagogia/article/ view/1234/682
Cabero J., Marín, V., \& Infante, A. (2011). Creación de un entorno personal para el aprendizaje: desarrollo de una experiencia. Edutec. Revista Electrónica de Tecnología Educativa, 38, 1-13. Recuperado de http://rabida.uhu.es/dspace/ bitstream/handle/10272/10798/Creacion_de_un_entorno_personal.pdf?sequence $=2$

Castellanos, A.; Sánchez-Romero, C. \& Calderero, J.F. (2017). Nuevos modelos tecnopedagógicos. Competencia digital de los alumnos universitarios. Revista Electrónica de Investigación Educativa, 19 (1), 1-9. https://doi. org/10.24320/redie.2017.19.1.1148

Churches, A. (2009). Taxonomía de Bloom para la era digital. Eduteka.org. Recuperado de http://www.eduteka.org/ TaxonomiaBloomDigital.php

Colomer, J.C., Sáiz, J. \& Bel, J.C. (2018). Competencia digital en futuros docentes de Ciencias Sociales en Educación Primaria: análisis desde el modelo TPACK. Educatio Siglo XXI, 36 (1),107-128. https://doi.org/10.6018/j/324191

Declaración de Bolonia (1999). Declaración conjunta de los ministros europeos de enseńanza, Bolonia, $12 \mathrm{de} \mathrm{ju-}$ nio de 1999. Recuperado de https://www.google. com/ search? source $=$ hp\&ei=EJk6W6K2MYOusAHPh63QCw\&q=Declaraci\%C3\%B3n+de+Bolonia.\&oq=Declaraci\%C3\%B3n+de+Bolonia.\&gs_l=psy-ab.3..0i22i$30 \mathrm{k} 1110.1257 .7016 .0 .7434 .25 .18 .0 .0 .0 .0 .963 .2304$ 0j4j6-2.7.0...0...1c.1.64.psy-ab..18.6.2302.0..0.106. eG5H5axpQ8A

Gabarda, V., Rodríguez-Martín, A. \& Moreno-Rodríguez, M. D. (2017). La competencia digital en estudiantes de magisterio. Análisis competencial y percepción personal del futuro maestro. Educatio Siglo XXI, 35(2), 253-274, 253274. https://doi.org/10.6018/j/298601

Gasser, U. \& Palfrey, J. (2008). Born digital: Understanding the first generation of digital natives. New York: Basic Books.

Gewerc, A. \& Montero-Mesa, L. (2015). Conocimiento profesional y competencia digital en la formación del profesorado. En caso del Grado de Maestro en Educación Primaria. Revista latinoamericana de tecnología educativa. 14(1), 31-43. Recuperado de http://dehesa.unex.es/bitstream/ handle/10662/3369/1695-288X_14_1_31.pdf?sequence $=1 \&$ isAllowed $=y$

Giones-Valls, A. \& Serrat-Brustenga, M. (2010). La gestión de la identidad digital: una nueva habilidad informacional y digital. BiD: textos de información y documentación, 24. http://dx.doi.org/10.1344/105.000001545

Gisbert, M. \& Esteve, F. (2011). Digital Leaners: la competencia digital de los estudiantes universitarios. La cuestión universitaria, 7, 48-59. Recuperado de http://polired.upm.es/index.php/lacuestionuniversitaria/article/ view/3359/3423

González, V., Román, M., \& Prendes, M. (2018). Formación en competencias digitales para estudiantes universitarios basada en el modelo DigComp. Edutec. Revista Electrónica De Tecnología Educativa, (65), 1-15 (391). 
https://doi.org/10.21556/edutec.2018.65.1119

González, L. A., Cárdenas, J. A. \& Arellano, J. C. (2017). Desarrollo de habilidades del pensamiento de orden superior a través de actividades de desempeño. Anfei Digital, 6, 1-9. Recuperado de http://www.anfei.org.mx/ revista/index. php /revista/article/view/360/1002

INTEF (2017). Marco Común de Competencia Digital Docente. Madrid: Ministerio de Educación, Cultura y Deporte.

Moreno-Rodríguez, M.D.; Gabarda, V. \& Rodríguez-Martín, A.M. (2016). Alfabetización informacional y competencia digital en estudiantes de magisterio. Profesorado. Revista de currículum y formación del profesorado, 22, (3), 253269. Recuperado de http://revistaseug.ugr.es/index.php/ profesorado/article/view/8001. https://doi.org/10.30827/ profesorado.v22i3.8001

Napal, M.; Peńalva-Vélez, A. \& Mendióroz, A.M. (2018). Development of Digital Competence in Secondary Education Teachers' Training. Education Sciences, 8 (104), 1-12. https://doi.org/10.3390/educsci8030104

Núñez-López, S., Ávila-Palet, J. E., \& Olivares-Olivares, S. L., (2018). El desarrollo del pensamiento crítico en estudiantes universitarios por medio del aprendizaje basado en problemas. Revista Iberoamericana de Educación Superior, 8(23), 126-138. https://doi.org/10.22201/iisue.20072872e.2017.23.3012

Snell-Siddle, C., Sarah, S \& Fisher, D. (2017). Tools of the trade: can mobile technologies enhance the learning experience in a tertiary environment? MIER Journal of Educational Studies, Trends \& Practices, 7(1), 14-23. Recuperado de http://www.mierjs.in/ojs/index.php/mjestp/article/ view/138/123

Pedró, F. (2009). New millennium learners in higher education: evidence and policy implications. Paris: Centre for Educational Research and Innovation (CERI). OECD.

Pérez-Ferra, M., Quijano-López, R. \& Ocaña-Moral, Ma . T. (2013). El profesorado universitario ante el Espacio Europeo de Educación Superior: dos años después. Educatio Siglo XXI, 31 (2), 235-253. Recuperado de http://revistas. um.es/educatio/article/view/187611

Ramírez, D. \& Arellano, L. (2015). Problemáticas legales de la gestión cultural en la era digital. II Encuentro de Gestión Cultural. Tlaquepaque, (Jalisco), 14 L 17 de octubre. Recuperado de http://observatoriocultural. udgvirtual.udg.mx/ repositorio/ handle/123456789/285

Rangel, A. (2018). Tecnologías de la Información y la Comunicación en la Educación Superior: una revisión documental. Pixel Bit, 52, 125-137. https://doi.org/10.12795/ pixelbit.2018.i52.09

Sandoval, P.; Rodríguez-Alveal, F. \& Maldonado, A.C. (2017). Evaluation of digital and pedagogical literacy in ICT based on the opinions of Initial Teacher Education students. Educ. Pesqui., 43, (1), 127-143. https://doi.org/10.1590/ s1517-9702201701154907

Solarte, F. N. J., Enriquez, E. R. \& Benavides, M del C.
(2015). Metodología de análisis y evaluación de riesgos aplicados a la seguridad informática y de información bajo la norma ISO/IEC 27001. Revista Tecnológica ESPOL, 28 (5), 492-507. Recuperado de http://www.rte.espol.edu.ec/ index.php/ tecnologica/article/view/456/321

Tejada, J. \& Pozos, K. (2018). Nuevos escenarios y competencias digitales docentes: hacia la profesionalización docente con TIC. Revista de currículo y profesorado, 22, (1), 25-51. Recuperado de https://recyt.fecyt.es/index.php/ profesorado/ article/view/ 63620/38691

Tondeur, J., Aesaert, K., Pynoo, B., van Braak, J, Fraeyman, N. \& erstad, Ol (2015). Developing a validated instrument to measure preservice teachers' ICT competencies: Meeting the demands of the 21 st century. British Journal of Educational Technology, 50(1), 23 - 39. Recuperado de https:// onlinelibrary.wiley.com/journal/14678535

Torres, S. A. \& Jaimes, K. (2015). Producción de conocimiento mediado por TIC: cuerpos académicos de tres universidades Públicas estatales de México. Revista Electrónica Sinéctica (44). Recuperado de http://www.redalyc.org/articulo.oa?id=99832951002

Velázquez-Sortino, M., Gómez-Zermeño, M. \& Alemán de la Garza, L. (2017). Interacciones en un curso en línea, abierto y masivo para docentes. Propuesta para un modelo de análisis. Digital Education Review, 31, 149-175. 